\title{
Da Maternidade A Construção De Uma Família: Narrativas De Meninas Que Residem Em Uma Instituição De Acolhimento
}

\author{
De La Maternidad Hasta La Construcción De Una Familia: Narrativas De \\ Las Niñas Que Viven En Una Institución De Acogida
}

\author{
From Motherhood To The Construction Of A Family: Narratives Of Girls \\ Living In A Host Institution
}

Lóry Da Silveira Ribeiro'

Josiane Vian Domingues ${ }^{2}$

\begin{abstract}
Resumo
Este trabalho tem como objetivo investigar alguns sentidos produzidos sobre maternidade para meninas que residem em uma instituição de acolhimento na cidade de Pelotas/ RS. Para tanto, foi utilizado enquanto aporte teórico e metodológico a abordagem dos Estudos Culturais, especificamente utilizando a produção de narrativas enquanto metodologia. O grupo focal serviu como inspiração para a produção dos dados, contando com a participação das quatro meninas que residiam na instituição naquele momento. Me utilizei do grupo focal utilizando diferentes artefatos disparadores tais como: revistas, desenhos, músicas. A família foi uma temática que apareceu fortemente durante os quatro encontros com as meninas. A mesma surgiu a partir da ideia de maternidade, logo no primeiro encontro, por conta do zelo que as meninas tinham umas com as outras, principalmente com a mais nova, de 2 (dois) anos. Ao analisar os relatos e letras das músicas que as meninas pediam, foi possível compreender que existe um imaginário de família hegemônica/ tradicional que as produzem colocando que outras formas de família não eram entendidas como corretas. Durante a pesquisa foi possível perceber que vai além da maternidade, mas de um imaginário e idealização de construção de uma família.
\end{abstract}

Palavras-Chave: Família; Instituição de Acolhimento; Meninas; Maternidade; Narrativas.

\section{Resumen}

Este trabajo tiene como objetivo investigar algunos sentidos producidos sobre maternidad para niñas que residen en una institución de acogida en la ciudad de Pelotas / RS. Para ello, se utilizó como aporte teórico y metodológico el abordaje de los Estudios Culturales, específicamente utilizando la producción de narrativas como metodología. El grupo focal sirvió como inspiración para la producción de los datos, contando con la participación de las cuatro niñas que residían en la institución en aquel momento. Me he utilizado del grupo focal utilizando diferentes artefactos disparadores tales como: revistas, dibujos, canciones. La familia fue una temática que apareció fuertemente durante los cuatro encuentros con las niñas. La misma surgió a partir de la idea de maternidad, luego en el primer encuentro, por el celo que las niñas tenían unas con las otras, principalmente con la más joven, de 2 (dos) años. Al analizar los relatos y letras de las canciones que las niñas pedían, fue posible comprender que existe un imaginario de familia hegemónica / tradicional que las produce poniendo que otras formas de familia no eran entendidas como correctas. Durante la investigación fue posible percibir que va más allá de la maternidad, pero de un imaginario e idealización de construcción de una familia.

Palabras Claves: la familia; Institución de acogida; niñas; la maternidad; Narrativas.

\footnotetext{
${ }^{1}$ Mestrado em andamento em Educação na Universidade Federal do Rio Grande; RS; Brasil; lory94@ gmail.com

2 Doutora em Educação em Ciências: química da vida e saúde pela Universidade Federal do Rio Grande; jo_pedagoga@yahoo.com.br
} 


\begin{abstract}
This work aims to investigate some meanings produced on maternity for girls residing in a host institution in the city of Pelotas / RS. For that, it was used as a theoretical and methodological contribution to the approach of Cultural Studies, specifically using the production of narratives as methodology. The focus group served as inspiration for the production of the data, with the participation of the four girls who resided in the institution at that time. I used the focus group using different trigger artifacts such as magazines, drawings, songs. The family was a theme that appeared strongly during the four encounters with the girls. The same arose from the idea of motherhood, at the first meeting, because of the zeal that the girls had with each other, especially with the youngest, of two (2) years. In analyzing the reports and lyrics of the songs that the girls asked for, it was possible to understand that there is a hegemonic / traditional family imaginary that produces them by placing other forms of family as not being understood as correct. During the research it was possible to perceive that it goes beyond the maternity, but of an imaginary and idealization of construction of a family.
\end{abstract}

Keywords: Family; Host institution; Girls; Maternity; Narratives.

\title{
1. Introdução
}

Esse trabalho é o fragmento de uma pesquisa maior intitulada “A produção dos corpos de meninas em uma Instituição de Acolhimento", a qual foi realizada como Trabalho de Conclusão de Curso em Educação Física na Universidade Federal do Rio Grande - FURG. Na Esta investigação em especifico apresenta como objetivo principal investigar alguns sentidos produzidos sobre maternidade para meninas que residem em uma instituição de acolhimento na cidade de Pelotas/ RS.

Para produzir os dados da pesquisa, foram realizados um total de quatro encontros, com cerca de 2 horas cada um, com uma média de 4 a 5 meninas por encontro, variando dependendo de quem estava na instituição durante os sábados a tarde, dias que a produção dos dados foi realizada. A temática inicial da pesquisa com esse grupo de meninas foi "corpo" e a partir do que elas narravam ao longo dos encontros, foram sendo pensadas outras temáticas a serem discutidas, além dos artefatos disparadores para que fosse possível realizar os encontros. Assim acabaram surgindo 3 temáticas, sendo elas: família e maternidade, identidade e sexualidades. A temática abordada neste texto em específico é família e maternidade.

O aporte teórico e metodológico aconteceu a partir da abordagem dos Estudos Culturais, considerando as culturas em que as meninas que fizeram parte desta pesquisa estão inseridas, as quais estão produzindo-as constantemente. Essa investigação aconteceu por meio da produção de narrativas das participantes, pois entendo que estas merecem ser ouvidas, pois são sujeitos na sua própria história, além de serem produzidas e produtoras de culturas.

Para realizar a produção das narrativas, foi utilizada como inspiração a ferramenta para produção de dados compreendida como grupo focal. $\mathrm{O}$ grupo focal é produzido através da seleção dos participantes que discutirão sobre um tema, onde todos devem conhecer ou ter 
alguma característica em comum Gatti, (2005). Este grupo envolve atividades coletivas, em que poderão ser utilizados diferentes artefatos disparadores tais como: revistas, propagandas, desenhos, músicas, filmes, entre outros. Em outras palavras, foram utilizadas algumas características de tal ferramenta para produzir o diálogo com as meninas. Tal inspiração se deu através do trabalho em grupo, onde eram levadas questões e diferentes artefatos disparadoras. Importante salientar que as temáticas que iam emergindo não ficaram presas em um único encontro, ou seja, as falas das meninas iam e voltavam a todo o momento dentro das temáticas. Esse fato potencializou ainda mais a pesquisa.

Assim, este texto buscou analisar os sentidos produzidos sobre família e maternidade, a partir da fala das meninas moradoras de uma instituição de acolhimento. A partir do exposto, para buscar responder o objetivo proposto, esse texto foi organizado da seguinte maneira: no primeiro momento foi desenvolvido uma breve discussão teórica acerca de alguns sentidos produzidos sobre maternidade, no segundo momento foram apresentados os achados da pesquisa e por fim algumas considerações finais, as quais não têm a pretensão de encerrar o assunto, mas abrir possibilidades para novas discussões.

\section{Alguns apontamentos sobre maternidade}

Existe uma produção de redes discursivas que enunciam a maternidade como algo semelhante para todas as mulheres, ou seja, existe uma norma considerada como correta para ser mãe. Em outras palavras, ser mãe seria igual em qualquer época, local e cultura, como se existisse um padrão para a maternidade e dependendo se esse padrão foi seguido ou não, as mulheres são situadas entre mães "boas" ou "ruins".

Sobre isso MOREIRA and NARDI (2009, p. 576) destacam que:

O reconhecimento da maternidade através dessa norma segue a rede enunciativa que determina, por exemplo, o número de filhos adequado, o tempo e a idade certos de ser mãe, as condições (econômicas) para a maternidade. Enunciados que, associados a diversos discursos, emprestam legitimidade a certos modos de ser mãe, passando a ter maior valor social.

Como os autores trazem a padronização dos modos de ser mãe e logo de se ter uma família, se da em diversos discursos, um destes é o da quantidade de filhos, que é aprovada e que foi sendo modificada ao longo dos anos. Ainda segundo os autores MOREIRA and NARDI (2009, p. 578):

Se antes famílias com muitos filhos eram famílias com mais de 10, hoje uma família com mais de dois já é considerada grande. Além disso, ter muitos filhos era sinônimo de uma família saudável, jovem, produtiva. Hoje, uma 
família muito grande é tida como irresponsável (não se planejou, não se cuidou), ou seja, uma família desleixada e fortemente associada à pobreza.

Dependendo do momento histórico e dos espaços sociais em que os sujeitos estão inseridos, os discursos sobre as formações familiares vão se modificando. Esses enunciados acontecem desde o momento da fecundação, onde o corpo da mulher é disciplinado para que ela se torne uma "boa mãe". Para que isso aconteça, uma série de estratégias e tecnologias (principalmente médicas) são desenvolvidas, ditando questões como, por exemplo, a alimentação, a prática ou não de exercícios físicos, a realização de Pré-natal, entre outras. Ao falar sobre os modos de vigilância e regulação nos discursos sobre a maternidade, Meyer (2005, p. 83, 84) descreve que:

\footnotetext{
As redes de poder-saber, aqui delineadas, atravessam e constituem determinados tipos de conhecimento que sustentam e conformam políticas e programas públicos, ênfases educativas, instrumentos de diagnóstico e modos de assistir e monitorar mulheres-mães, na atualidade. São contingências que contribuem para re-significar a relação mãe-filho e re-inscrever o corpo materno em um poderoso regime de vigilância e regulação forjando discursos sobre a maternidade [...].
}

Essas articulações modificam os enunciados sobre a maternidade que devem ser entendidos como verdadeiros e assim determinam os modos como as mães devem agir e sentir em relação aos seus filhos, aos seus próprios corpos, relacionamentos, etc.

Nesse sentido, é possível considerar que as meninas desde cedo são envolvidas por uma rede de discursos que determinam formas corretas de se ter uma família, principalmente o construir-se mãe como algo naturalizado. É possível, perceber isso através de algumas narrativas trazidas pelas meninas que estão institucionalizadas, as quais estarão sendo trazidas no desenvolvimento do texto.

\section{Da maternidade a construção de uma família}

A temática família perpassou todos os encontros com as meninas, porém não há como afirmar que tal emergiu pelo fato das meninas estarem em uma instituição de acolhimento e terem sido retiradas de suas moradias. Essa foi uma temática que não estava sendo prevista como categoria de análise ao iniciar o trabalho, apesar disso ela atravessou em todos os encontros, principalmente por conta da maternidade. Contudo, ao longo dos encontros foi possível perceber que vai além da maternidade, mas de um imaginário e idealização da construção de uma família.

Desde o momento que cheguei a casa, pude identificar que um ponto importante para aquelas meninas é a maternidade, pois elas, ao cuidarem umas das outras se nomeavam como suas mães, tinham um olhar cuidadoso principalmente sobre a mais nova de todas, que tinha 
apenas 2 anos, inclusive ela estava junto em todos os nossos encontros para que as maiores pudessem cuidar dela. Esse zelo era tão grande que até mesmo as educadoras percebiam. Nos diálogos a seguir, é possível visualizar a noção de maternidade entrando em ação:

Diálogo 1:

Eu: Vocês ajudam a cuidar da pequena?

Maria (9 anos): Na verdade eu cuido dela

(Grupo focal- 1 de julho de 2017)

Diálogo 2:

Michele (13 anos): Sabia que agora eu sou a mãe delas aqui?

Maria (9 anos): das três não, só de duas (demonstrando que ela não era uma das "filhas")

(Grupo focal - 1 de julho de 2017)

Diálogo 3:

Educadora: Primeiro (antes de irem para o salão que aconteceria o grupo focal), tem que botar o sapatinho nela.

Camila (9 anos): Ela vai ir?

Educadora: Vai. Da outra vez ela foi, ela não incomodou né?

Eu: Não

Educadora: É que ela é muito apegada aquela outra, a maninha, ela é a mãezona dela aqui na casa.

(Grupo focal- 8 de julho de 2017)

Esses diálogos mostram que a maternidade exerce um papel na produção das identidades daquelas meninas. Durante a pesquisa, uma das questões que chamou bastante a atenção é que ao observar, percebi essas marcas exclusivamente nas meninas. Em outras palavras, em nenhum momento ouvi os meninos se considerando ou serem considerados como pais de nenhuma das outras crianças.

Para Silva (2007, p. 41) "é possível dizer que a promoção deste modelo de feminilidade, voltado para o doméstico e para a maternidade, constituiu-se numa peça 
importante no jogo de gerenciamento da família e, por conseguinte, no nascimento da família nuclear moderna."

Mais adiante, a autora continua (2007, p. 68):

\begin{abstract}
ao ver a maternidade como uma construção histórica e cultural, ou seja, como algo que não esta alojado na "natureza feminina" ou num suposto "instinto biológico", suspeita que são acionadas e produzidas, [ ...] uma série de práticas que visam "ensinar" as mães a serem "mães de um certo modo", fazendo circular determinados saberes e verdades sobre elas. Estas práticas ensinam as mães a cuidarem e a vigiarem as práticas dos filhos, além de cuidarem de si próprios para que não procriem.
\end{abstract}

A partir das ideias da autora e dos diálogos produzidos nos encontros, faz com que seja entendido que ainda hoje existente uma visão de que as questões do cuidado devem fazer parte do cotidiano das meninas. Um exemplo disso é produzido quando a diretora zela sobre a sexualidade de uma das meninas por medo que a mesma engravide, porém não pareceu se preocupar com as possibilidades dos meninos se tornarem pais, pelo menos, não fez relato algum sobre isso.

As crianças que moram nessa instituição acabam constituindo novas formas de família, cuidam e zelam pelo próximo. Tal formação foge de um modelo tradicional e hegemônico que é produzido em relação a família. Tradicionalmente, a forma tida como correta é aquela constituída por um casal heterossexual que temos seus papéis e funções bem definidos, como a mãe e o pai e os seus filhos. Apesar de fazerem formações diversas, foi possível perceber que as meninas desejam constituir esse modelo de família hegemônica, onde existe os papeis bem demarcados para um pai, uma mãe e seus filhos.

Sobre esse modelo de família tradicional que é produzido e que diversas vezes é reproduzida, sobretudo pela mídia, Hennigen (2008, p. 168, 169):

\begin{abstract}
aponta uma forma de ser hegemônica, aquela que, em função dos jogos de poder, é colocada como a forma natural e correta de ser família.[...] os arranjos familiares são hierarquizados: a família composta por pai, mãe e filhos - genericamente chamada de tradicional é desejada; as posições que se afastam deste modelo são referidas como problemáticas, sendo que o ponto frágil, o mais afetado, são as crianças. Mensagem forte, que certamente não impede novas composições familiares, mas que fomenta expectativas, mobiliza ansiedade, culpa e temor, aponta riscos em vez de possibilidades, dimensões importantes e que tem peso nos nossos modos de ser e sentir.
\end{abstract}

É possível perceber o desejo das meninas por querer ter essa família tradicional, demonstrando que outras formas de ser família são dadas como não corretas ou de menor importância. Um exemplo disso pode ser visto através do diálogo, em que uma das meninas nega o pai biológico pelo fato dele não possuir uma posição social considerada correta:

Stela (16 anos): Eu não tenho família, eu não tenho pai, eu não tenho mãe. 
Maria (9 anos): Não? Tu não tinha pai?

Stela: Pai que é atirado nas drogas, que não tá nem ai pra ti, não, eu não tenho e que rouba, não muito obrigado, prefiro não ter.

(Grupo focal - 22.07.2017)

A ideia de que a menina não teria uma família por não ter as condições dadas como corretas, demonstra o quanto socialmente se construiu uma ideia de que precisa existir esses sujeitos com seus papéis muito bem demarcados para a existência de uma formação familiar.

Essa família que é vista como possível somente se estiver dentro desse modelo ideal, também pode ser visualizada na letra da música que as meninas idolatram, onde os papéis são bem demarcados: a mulher deverá ser "inocente" até encontrar o "homem de verdade" com quem irá formar uma família, com a mãe, o pai e o filho.

Além disso, durante a letra é possível perceber que para a formação da família acontecer, os mesmos devem seguir passos: primeiro namorar, noivar, casar na igreja, e somente depois do casamento engravidar e ter seus filhos, para que essa família então possa ser formada.

Música Tragédia-MC Moreno

Era uma vez

Uma história de love na cidade

De uma menina inocente

E um homem de verdade

E ele procurava uma mulher pra ele amar

E ela à procura de um homem à se relacionar

E um belo dia na rua tudo ia mudar

Ela saindo com as amiga, ele indo trabalhar

Num desacerto com o farol aberto, distraída

Só dava pra mim ouvir o grito das suas amiga

Miga cuidado tem um carro na sua direção

Quando me deparei ela já estava no chão

Parei a moto e desci pro um socorro prestar

E foi ai que eu percebi que ia me apaixonar

Eu perguntei se ela tava muito machucada

Ela me disse que só tava com a perna ralada

Levantei ela e falei cuidado ai na rua

Toma o meu número e me liga pra qualquer ajuda

Segui o meu caminho e continuei meu dia 
Mas não tirava da cabeça aquela menina

Cheguei em casa, deitei no sofá, liguei a tv

E só pensava quando que de novo eu ia ver

Peguei no sono e acordei com uma ligação

Era uma voz tão doce que tocou meu coração

Era aquela menina mais cedo do acidente

Disse que eu fui muito gentil

Que eu era diferente

Falou que queria me ver, chamei ela pra sair

Vamos jantar, pegar um cinema pra se distrair

E depois do cinema levei ela pra minha casa

Era a mulher que eu sonhava pra ser minha amada

Dois anos se passaram, decidimos nos casar

Avisa os familiares e vamo pro altar

E no dia do casamento ela tava linda

Era a mulher que eu sonhava para a minha vida

Tempo passou e ela descobriu que tava grávida

Fiquei feliz vamo aumentar e preparar a casa

E no final da gravidez ela tava tão bela

Só que numa noite chuvosa aconteceu a tragédia

E voltando de um restaurante com a nossa família

Guardando o carro na garagem, uma armadilha

Dois bandidos encapuzados, queriam roubar

E eu sem ter o que fazer falei pode levar

$E$ de repente eu escutei um barulho de um tiro

Pegou no peito dela e os bandidos fugiram

Desesperado eu liguei para o resgate

Chegando lá o doutor me disse que era tarde

Que a bala foi fatal e isso fez ela morrer

Mas ainda dava pra salvar a vida do bebê

Então ele nasceu

Em uma cena cruel

Filho eu te amo, aqui na terra

E sua mãe no céu.

A partir dos diálogos construídos com as meninas, bem como com a letra da música na qual elas gostam, é possível perceber o quanto é importante para elas a ideia de família tradicional. Por mais que, em algumas falas, as meninas neguem os seus pais, por eles não desempenharem as funções adequadas na sociedade, em outros elas demarcam a falta deles. As meninas identificam aquela instituição como os seus lares, mas ao mesmo tempo, 
demonstram sentir falta desse imaginário familiar, o qual é composto por seus pais e irmãos. Isso ficou evidente ao desenharem a família que seriam elas, os seus 6 irmãos, que também estavam abrigados e os pais. No desenho, elas colocavam todos dentro da instituição, como aquela sendo a casa/lar daquelas meninas, faltando apenas aquelas duas figuras: o pai e a mãe.

Além disso, através da música também foi possível ponderar a ideia de uma construção familiar por parte das meninas, onde elas apresentam o desejo de encontrar um "homem de verdade" com quem poderiam construir as suas próprias famílias.

\section{Considerações Finais}

Este trabalho teve como objetivo investigar alguns sentidos produzidos sobre maternidade para meninas que residem em uma instituição de acolhimento na cidade de Pelotas/ RS. Esse trabalho foi proposto com a intenção de fazer pesquisa com as crianças e não sobre elas, por mais que se perceba as fragilidades disso, apesar de ser um olhar próprio sobre aquilo que elas falavam, a todo instante foi tentado entrar no universo delas, tentando falar a linguagem delas e escutar aquilo que elas manifestavam.

A pesquisa foi realizada com as meninas que residem em uma instituição, pois é possível perceber o quanto as instituições de acolhimento buscam educar as crianças e adolescentes tanto quanto outros espaços educativos, como as escolas, as igrejas ou as próprias famílias.

A família foi uma temática que apareceu fortemente durante os encontros. A mesma surgiu a partir da maternidade, logo no primeiro encontro, por contado zelo que as meninas tinham umas com as outras, principalmente com a mais nova. Além disso, ao analisar os relatos e letras das músicas que as meninas pediam, foi possível compreender que existe um imaginário de família hegemônica/tradicional que produz aquelas meninas colocando que outras formas de família não eram entendidas como corretas.

\section{Referências}

GATTI, Bernardete Angelina. Grupo focal na pesquisa em ciências sociais e humanas.In: Série Pesquisa em Educação. Líber Livro, 2005.

HENNIGEN, I. A família que aparece na mídia: hegemonia de um modelo. In: Psico, v. 39, n. 2, 2008. https://www.cifraclub.com.br/mc-moreno/tragedia/ <acesso em 15-10-2018> 
MEYER, D. E. A politização contemporânea da maternidade: construindo um argumento. Revista Gênero, v. 6, n. 1, p. 81-104, 2005.

MOREIRA, L. E.; NARDI, H. C. Mãe é tudo igual? Enunciados produzindo maternidade (s) contemporânea (s). Estudos Feministas, p. 569-594, 2009.

SILVA, M. M.. Família na escola: olhando fotografias, lendo textos culturais. Dissertação (Mestrado em Educação).Universidade do Vale do Rio dos Sinos, São Leopoldo,2007. 